DOE /PC/89773-2

\title{
A MATHEMATICAL MODEL FOR TAR RELEASE IN RAPID DEVOLATILIZATION OF A SOFTENING BITUMINOUS COAL
}

\author{
Second Technical Progress Report \\ Sarakorn Gerjarusak, William A. Peters, and Jack B. Howard \\ Energy Laboratory and Department of Chemical Engineering \\ MASSACHUSETTS INSTITUTE OF TECHNOLOGY \\ Cambridge, Massachusetts 02139
}

\section{DISCLAIMER}

This report was prepared as an account of work sponsored by an agency of the United States Government. Neither the United States Government, nor any agency thereof, nor any of their employees, makes any warranty, express or implied, or assumes any legal liability or responsibililty for the accuracy, completeness or usefulness of any information, apparatus, product, or process disclosed, or represents that its use would not infringe privately owned rights. Reference herein to any specific commercial product, process, or service by trade name, trademark, manufacturer, or otherwise, does not necessarily constitute or imply its endorsement, recommendation, or favoring by the United States Government or any agency thereof. The views and opinions of authors expressed herein do not necessarily state or reflect those of the United States Government or any agency thereof.

Submitted to the United States Department of Energy Pittsburgh Energy Technology Center

Attention: Dr. Philip M. Goldberg

PREPARED FOR THE UNITED STATES DEPARTMENT OF ENERGY Under Contract No. DE-FG22-89PC-89773

Date Submitted: December, 1990

"US/DOE Patent Clearance is not required prior to the publication of this document." 
Abstract

The rapid-heating, fast response plastometer has been reassembled and restored to its working conditions. The plastometer was calibrated with various viscosity standards. The ratio of the observed viscosity to the actual viscosity was found to range from 1.2 to 2.8 . The higher observed viscosity values were attributed to friction and misalignment of the shearing disk. In addition, the viscosity readings varied from one run to another because the distance between the moving disk and the stationary plate could not be maintained constant. Use of a low friction bearing for the shearing disk's shaft and the cone-and-plate configuration have been suggested as remedies to these problems.

\section{DISCLAIMER}

This report was prepared as an account of work sponsored by an agency of the United States Government. Neither the United States Government nor any agency thereof, nor any of their employees, makes any warranty, express or implied, or assumes any legal liability or responsibility for the accuracy, completeness, or usefulness of any information, apparatus, product, or process disclosed, or represents that its use would not infringe privately owned rights. Reference herein to any specific commercial product, process, or service by trade name, trademark, manufacturer, or otherwise does not necessarily constitute or imply its endorsement, recommendation, or favoring by the United States Government or any agency thereof. The views and opinions of authors expressed herein do not necessarily state or reflect those of the United States Goveinment or any agency thereof. 


\section{Introduction}

The goal of this research is to provide new, quantitative understanding of the high heating rate plastic behavior of different bituminous coal, especially data and a global model relating transient apparent plasticity to transient intra-coal metaplast inventories. A rapid-heating, fast response plastometer developed by Fong [1] will be used to generate coal plasticity data for a wide range of conditions of interest in modern coal utilization including high heating rates (up to $600 \mathrm{~K} / \mathrm{s})$, elevated temperatures $(\leq 1300 \mathrm{~K})$, for different coal types, with and without the presence of oxidizing $\left(\mathrm{O}_{2}, \mathrm{CO}_{2}\right)$ and reducing $\left(\mathrm{H}_{2}\right)$ gases.

\section{The Plastometer}

The fast-response plastometer allows the rapidly changing plasticity of a softening coal to be determined as a function of time at various pyrolysis conditions (i.e. heating rate, temperature, pressure, etc.). The technique is to measure the torque required to rotate at constant angular velocity, and hence constant average shear rate, a thin disc embedded in a thin layer of coal, initially packed as fine particles and confined between two heated metal plates.

A schematic of the plastometer is shown in Figure 1. A torque transducer is connected at one end to the shearing disc and at the other end to a gearmotor driven by a speed controller. The shearing disc rotates inside a chamber formed between two metal plates and filled with ground coal. The plates are mounted to two electrodes and heated with electrical current up to 500 amp.The digital timers and carbon rheostats control the presclected time-temperature profiles. The signal of the transducer is amplified and then recorded by an electronic recorder with a maximum data acquisition rate of 1 point per msec $[1,2]$. 


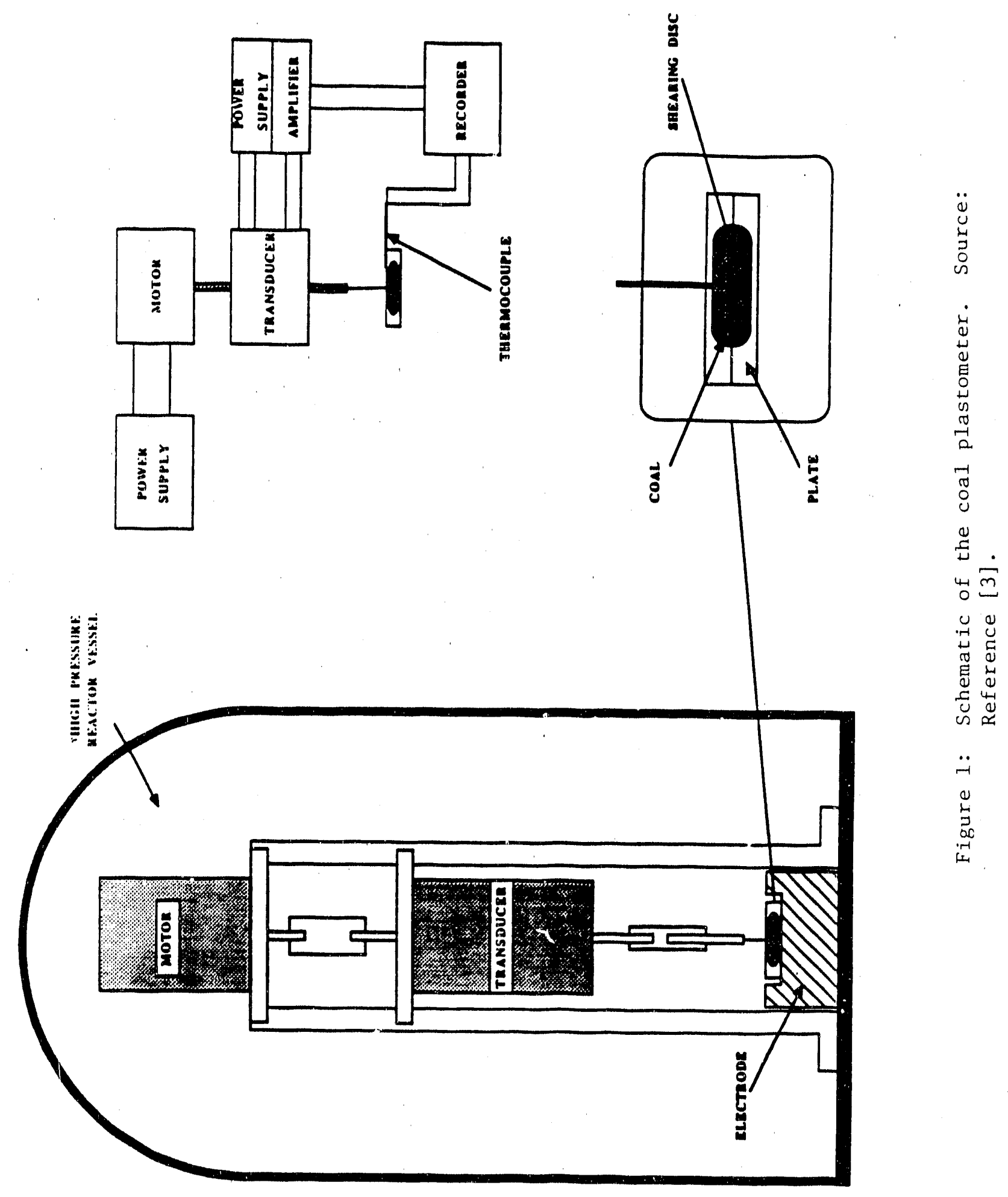




\section{Work during This Reporting Period.}

The chamber and gas lines of the recently reassembled plastometer were first checked for leaks. The system was pressurized with helium up to $10 \mathrm{~atm}$, and no leaks were found from the chamber and gas lines. The system's atmosphere was also evacuated using a vacuum pump. The plastometer system was able to hold the pressure of near vacuum for at least 30 minutes.

The electronic recorder was sent to the manufacturer because it was unable to provide steady readings when given a constant DC voltage input from a DC power supply. After servicing, the recorder showed the expected behavior of providing steady voltage readings when exposed to DC input voltages over the range of $50 \mathrm{mV}$ to $10 \mathrm{~V}$.

A new thermocouple was installed to measure the temperature of the shearing chamber. Empty metal plates were placed between the electrodes, and the rheostat was set to provide current for a $400 \mathrm{~K} / \mathrm{s}$ heating rate. The heating circuit was activated, and a heating rate of approximately $400 \mathrm{~K} / \mathrm{s}$ was observed. The maximum temperature observed was $1200 \mathrm{~K}$, and holding temperatures of 800 and $1200 \mathrm{~K}$ were sustained for 1 to 3 seconds.

The motor and its speed controller were in good working condition. To test the transducer, a force is applied to the motor coupling, and torque readings were observed usirg the electronic recorder. It was apparent that higher torque readings were obtained when more force was applied.

To ensure the accuracy of the transducer readings, two viscosity standards ( $\mathrm{N} 450000$ and $\mathrm{N} 2700000$ ) made up of high molecular weight hydrocarbons were purchased from Cannon. Instrument to calibrate the plastometer. Unsteady torque readings were observed with the ratios of observed viscosity to actual viscosity ranging from 
1.2 to 2.8. A detailed discussion of calibration results is provided below..

\section{Calibration Results.}

Fong [1] related the plastometer's torque $(\tau)$ readings to the viscosity $(\eta)$ readings using the equation for a concentric rotating disk viscometer [4]:

$$
\eta=\frac{\tau / 2 \pi R^{3}}{\gamma_{R}} \times\left[3+\operatorname{dln}\left(\tau / 2 \pi R^{3}\right) / d \ln \gamma_{R}\right]
$$

where $\gamma_{R}=\Omega R / H$ is the shear rate at the disk radius of $R, \Omega$ is the disk angular velocity, and $\mathrm{H}$ is the distance between the parallel faces of the moving and the stationary disks. With two sets of plates and Newtonian fluid, the equation simplified to [1]:

$$
\eta=\frac{\tau / \pi R^{3}}{\gamma_{R}}
$$

The ratio of the observed viscosity to the actual viscosity $\left(b=\eta_{\text {obs }} / \eta_{a}\right)$ was found to be higher than one. In the present work, the values of b ranged from 1.2 to 2.8 , and the higher values were probably due to friction and/or misalignment of the motor and shearing disk coupling. The torque reading of each run was unsteady, but the time variations in torque were essentially periodic over a cycle of one complete revolution of the shearing disk (Figure 2.). The roughly periodic time variations in the torque readings are suspected to result from misalignment between the motor and the shearing disk. The misalignment resulted in friction between the shearing disk and the shearing chamber walls. In addition, $\mathrm{H}$ could vary from one run to another since there was no device incorporated between the shearing disk and the chamber walls to fix the distance between the disk and the stationary plates. With friction and misalignment minimized, the plastometer should provide accurate viscosity measurements for materials contained in the shearing chamber. 




S.e dx ${ }_{z}$ Ol 'XIISOJSIA 


\section{Future Plans}

The immediate plan is to modify the shearing disk and chamber to minimize friction and misalignment. A small bearing can be incorporated between the metal plate forming the upper wall of the shearing chamber and the shaft of the rotating disk, to minimize friction and misalignment. To eliminate the problem of variations in $\mathrm{H}$ as the shearing disk rotates, a cone can be used instead of a flat disk. With the tip of the cone just touching the bottom stationary plate, the distance between this plate and the cone is fixed and $\mathrm{H}$ at a given radius is nearly time stationary. The cone angle $(\theta)$ can be chosen to be small so that the shearing rate is the same at all radii between the center and circumference of the cone. The viscosity can be obtained from the measured torque using the equation of the cone-and-plate viscometer [4]:

$$
\eta=\frac{3 \tau / 2 \pi R^{3}}{\gamma_{R}}
$$

where $\tau, R$, and $\gamma_{R}$ are as defined earlier for the parallel-disk viscometer. The additional benefit of the cone-and-plate configuration is that a simple equation is obtained without the need to assume that the fluid is Newtonian. A schematic of a cone-andplate viscometer is shown in Figure 3.

The next step is to calibrate the heating rate and holding temperature with the rheostat settings. The goal is to exactly relate the rheostat settings to the heating rate and the holding temperature desired.

The plan is to then obtain plasticity data for various materials. One option is to study Pittsburgh No.8 Seam bituminous coal and to compare the resulting plasticity data to Fong's earlier results on this coal. 


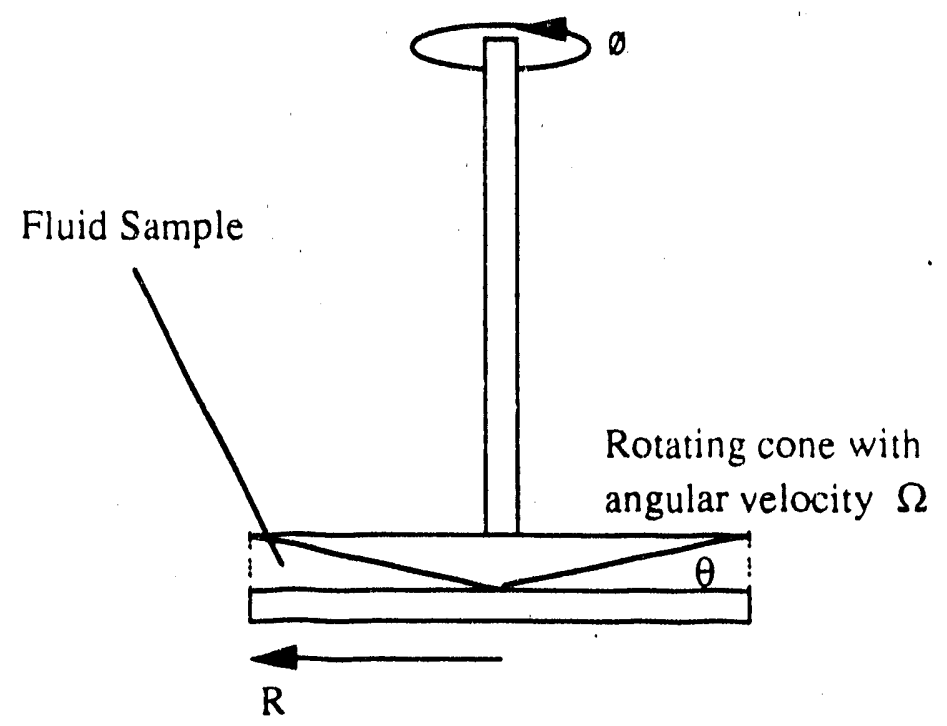

Figure 3. Cone-and-plate viscometer. $\Theta$ chosen to be very small, of the order of a few degrees. 


\section{Literature References}

1. Fong, W. S., W. A. Peters, and J. B. Howard, " Apparatus for Determining High Temperature Coal Plastic Behavior under Rapid Heating Conditions, " Review of Scientific Instruments, 56, 586-591, (1985).

2. Fong, W. S., "Plasticity and Agglomeration in Coal Pyrolysis," Sc.D. Thesis, Department of Chemical Engineering, MIT, Cambridge, MA, (1986).

3. Darivakis, G. S., W. A. Peters, and J. B. Howard, "Coal Plasticity at High Heating Rates and Temperatures: First Technical Report to the U.S. Department of Energy," Contract No. DE-FG22-89PC89773 (January; 1990).

4. Bird, R. B., R. C. Armstrong, and O. Hassager, Dynamics of Polymeric Liquids, Vol. 1, Wiley, New York, $(1977,1988)$ 

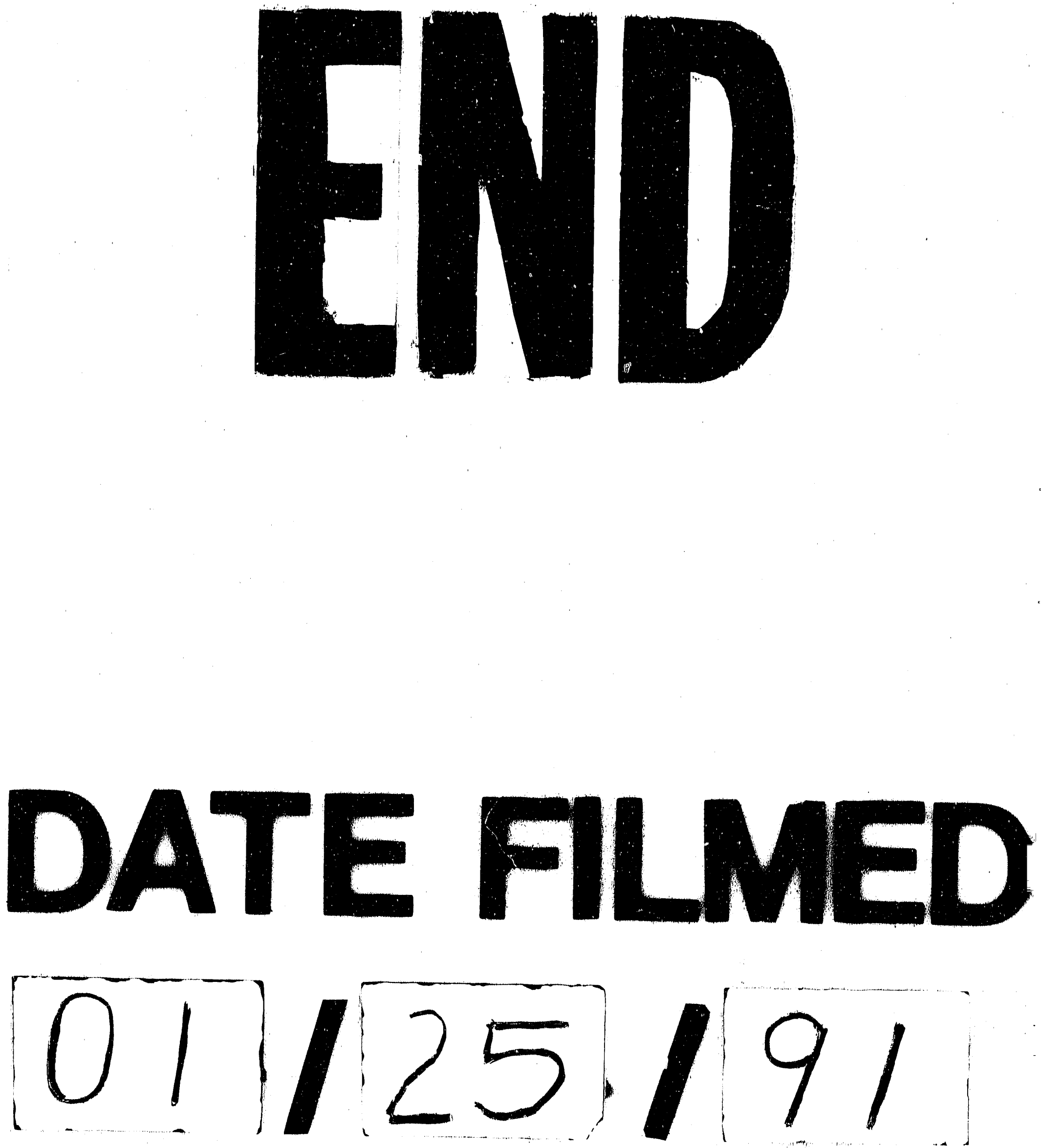
, 